\title{
Vegetation in the urban environment: microclimatic analysis and benefits
}

\author{
Argiro Dimoudi*, Marialena Nikolopoulou* \\ Centre for Renewable Energy Sources (CRES), 19th km Marathonos Avenue, Pikermi 190 09, Greece
}

\begin{abstract}
This paper describes work that was carried out by CRES, in the frame of the EU-funded Joule project "PRECis: assessing the potential for renewable energy in cities." The main aim of the project is to develop simplified parameters that describe the microclimate and environmental performance of different urban textures. One of the roles of CRES within the team was to describe simplified parameters for the use of vegetation in the urban context, which can eventually be used irrespective of site-specific characteristics for different climatic contexts and urban textures. Of particular interest is the effect of vegetation on microclimate: thermal effects, as well as the effect of vegetation on solar and daylight access. These affect the microclimate of the existing open spaces as well as the energy use of the surrounding buildings for heating, cooling and lighting, through shading, evapotranspiration, etc. Simple parametric studies were examined, to identify the thermal impact of vegetation in the urban environment, at the scale of the urban block, particularly as far as the reduction of air temperature is concerned. (C) 2003 Published by Elsevier Science B.V.
\end{abstract}

Keywords: Vegetation; Microclimate; Urban block; CFD analysis

\section{Introduction}

This paper describes part of the work of the EU-funded Joule project "PRECis: assessing the potential for renewable energy in cities". The main aim of the project was to develop simplified parameters that describe the microclimate and environmental performance of different urban textures, so that as the physical form of the urban texture is changed, the likely effect on environmental conditions, energy use and the potential for renewable energy can be determined. In such a framework, one of the roles of CRES within the project was the identification of simplified characteristics describing the effect of vegetation on microclimate, which can eventually be used irrespective of site-specific characteristics for different climatic contexts and urban textures. Of particular interest is the effect of vegetation on microclimate: thermal effects, as well as the effect of vegetation on solar and daylight access. These affect the microclimate of the existing open spaces as well as the energy use of the surrounding buildings for heating, cooling and lighting, through shading, evapotranspiration, etc.

To identify the thermal impact of vegetation in the urban environment, with respect to the reduction of air temperature, simple parametric studies were examined:

\footnotetext{
${ }^{*}$ Corresponding author. Tel.: +30-10-6603300; fax: +30-10-6603301.
}

(1) simulating vegetation through the basic physiology of the plant; (2) simulating the effect of a park, at the scale of the urban block, with CFD analysis. The former study provided an insight into plants' behaviour under different environmental conditions, understanding the string of inter-relationships between vegetation, climate and urban environment. The latter study investigated the thermal impact of vegetation, with respect to the reduction of air temperature in the urban context, employing CFD analysis for generic urban textures.

\section{Impact of vegetation in the urban environment}

The physical impact of vegetation in the urban environment affects the thermal environment, air quality and noise levels. The aim of this paper is to investigate the microclimatic effects of vegetation with respect to reducing air temperature, therefore mitigating the heat island effect, where most city centres experience significantly higher temperatures than the surrounding countryside. To be precise, vegetation mitigates the heat island not by cooling the air, but by warming the air less [1]. Vegetation reduces air temperature by direct shading of surfaces as well as by moderating solar heat gain through evapotranspiration of the plants, and conversion of incident solar radiation to latent heat. Furthermore, the resulting lower temperature leads to reduced long-wave radiation emitted from ground and 
leaves, as opposed to the surrounding artificial hard surfaces, thus subjecting people to a reduced radiant load.

More specifically, the microclimatic effect of trees is obtained through several processes:

(i) reduction of solar heat gains on windows, walls, and roofs through shading;

(ii) reduction of the building long-wave exchange with the sky as building surface temperatures are lowered through shading;

(iii) reduction of the conductive and convective heat gain by lowering dry-bulb temperatures through evapotranspiration during summer;

(iv) increase of latent cooling by adding moisture to the air through evapotranspiration.

Estimation of the decrease of ambient temperature, below the urban canopy, due to vegetation is therefore, critical.

\section{Characterising vegetation}

For modelling purposes, it was critical to identify simplified characteristics describing the effect of vegetation in the urban environment, which can eventually be used irrespective of site-specific characteristics for different climatic contexts and urban textures. Thus, different entities of vegetation have been identified:

(i) planar objects, such as planted pergolas and grass;

(ii) $3 \mathrm{D}$ objects, such as trees.

The values assumed as characteristic of the different phenomena, as collected from an extensive bibliographic survey, are presented below.

\subsection{Evapotranspiration}

Estimation of the reduction of urban air temperature due to evapotranspiration is important. This has been proposed [1] using published data of maximum evapotranspiration rates for different types of vegetation and the volume of air with which the cooled air is mixed, per unit time. The contribution of evapotranspiration, can be determined by using estimates of the reference evapotranspiration, $\mathrm{ET}_{0}$ which is the evapotranspiration rate of a reference crop, in mm per day, under specific climatological conditions. The evapotranspiration from a given vegetation type, $\mathrm{ET}_{\mathrm{c}}$, is determined by multiplying $\mathrm{ET}_{0}$ by a crop coefficient, $K_{\mathrm{c}}$ :

$\mathrm{ET}_{\mathrm{c}}=K_{\mathrm{c}} \times \mathrm{ET}_{0}$

For this purpose, a rich database of different plant species has been collected with their respective evapotranspiration characteristics $\left(K_{\mathrm{c}}\right)$ [2,3]. A crop coefficient of 0.7 has been employed, typical of trees such as olive and citrus. When the effect of different vegetation characteristics is examined in CFD analysis, a crop coefficient of 1.2 is assumed corresponding to tropical vegetation, such as banana trees. This is in order to compare the base case with the effect of maximum potential evapotranspiration, to the urban microclimate.

$\mathrm{ET}_{0}$, in respect, is calculated from the Jensen and Haise regression equation [4], relating potential evapotranspiration $\left(\mathrm{ET}_{0}\right)$ to the mean air temperature $\left(T_{\mathrm{a}}\right)$ and solar radiation absorbed $\left(R_{\mathrm{s}}\right.$, i.e. in terms of the evaporation equivalent to the solar radiation, $\mathrm{mm}$ per day):

$\mathrm{ET}_{0}=\left(0.0252 T_{\mathrm{a}}-0.078\right) R_{\mathrm{s}}$

This equation can be rewritten in terms of the incident solar radiation $(I)$ as $I(1-a)$, where $a$ is the albedo of the grass, assumed to be 0.2 :

$\mathrm{ET}_{0}=0.8\left(0.0252 T_{\mathrm{a}}-0.078\right) I$

For the current study, $\mathrm{ET}_{0}$ has been calculated from Eq. (3), assuming vegetation native to the Mediterranean area and climatic context for Athens, for July (mean daily incident radiation of $447 \mathrm{~W} / \mathrm{m}^{2}$ and mean daily ambient air temperature of $27.2^{\circ} \mathrm{C}$. This is then employed in Eq. (1), to derive the evapotranspiration rate of the vegetation specie under consideration.

\subsection{Transmission}

This parameter refers to the effect of vegetation on solar and daylight access and varies with the season, particularly for deciduous trees. It is particularly important for modelling the shading effect of vegetation on nearby buildings and open spaces. A value of 0.15 for summer and 0.80 for winter, for deciduous trees and 0.15 for evergreen has been employed.

\subsection{Albedo}

Albedo affects solar and daylight access, so it is also an important parameter for the thermal aspects of vegetation, as it affects the amount of incoming radiation on the site that is removed by evapotranspiration.

Average figures for albedo are around $0.20-0.25$ for vegetation. However, it is worth identifying the relative "ecological adaptation" [5] of vegetation, where species found in hot-dry climates with low rainfall and high evaporative demand have higher albedos, tending to reduce their solar-heat load.

A value of 0.30 is therefore employed, for the climatic context of Athens, for deciduous trees. For evergreen plants, the value to be used is 0.25 .

\subsection{Permeability}

This parameter relates to the permeability of vegetation to wind. As we are modelling only summer conditions, an average of 0.40 has been employed, extracted from literature. 


\section{Parametric studies}

Parametric studies of two different forms were carried out:

(i) employing the 'mathematical plant: transpiration model', at the immediate scale of the plant;

(ii) employing CFD analysis, with the PHOENICS programme, at the scale of the urban block.

The former study provided an insight into plants' behaviour under different environmental parameters and therefore, set the scene for understanding the string of interrelationships between vegetation, climate and the urban environment. The latter study investigated the thermal impact of vegetation, particularly with respect to the reduction of air temperature in the urban context, for the climatic context of Athens specifically. Simple parametric studies were examined with CFD-PHOENICS programme, at the scale of the urban block. The modelling work was undertaken by 'Sybilla' consulting engineers, working closely with CRES.

\subsection{Mathematical plant: transpiration model}

This is an iterative computer model, simulating the basic physiology of the plant [6], where the sequence of calculations is:

(i) transpiration rate of the plant, using environmental parameters;

(ii) heat balance of the plant;

(iii) changes in leaf temperature;

(iv) changes in water potential and finally;

(v) stomatal aperture of the leaves according to light intensity.

Comparisons were carried out for different ambient air temperatures within the range of $10-40{ }^{\circ} \mathrm{C}$, wind speed of $0.1,1$ and $10 \mathrm{~m} / \mathrm{s}$, all tested at a relative humidity of $50 \%$, and "photosynthetically active radiation" of $2000 \mathrm{mmol} /$ $\left(\mathrm{m}^{2} \mathrm{~s}\right)$. The comparison is shown in Figs. 1-2, whereas the most important findings are presented below.

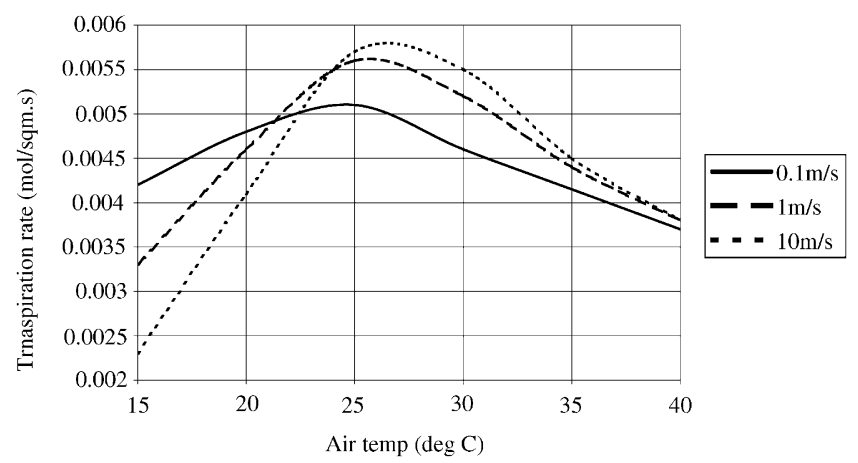

Fig. 1. Variation of the leaves' transpiration rate for different air temperatures, at different wind speeds.

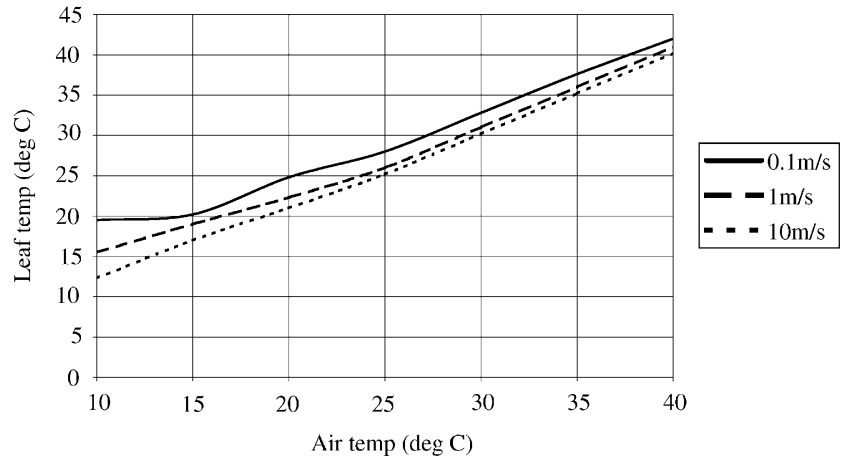

Fig. 2. Variation of the leaf temperature for different air temperatures, at different wind speeds.

\subsubsection{Evapotranspiration and leaf temperature}

Evapotranspiration rate is at a maximum and stomatal resistance at a minimum at air temperature of $25{ }^{\circ} \mathrm{C}$. Stomatal resistance increases as leaf temperature deviates upward or downward.

Evapotranspiration rate is higher for high wind speeds at air temperatures above $25^{\circ} \mathrm{C}$, and low wind speeds below $25{ }^{\circ} \mathrm{C}$. It is worth pointing out that at $40{ }^{\circ} \mathrm{C}$ and wind speed of $0.1 \mathrm{~m} / \mathrm{s}$, the transpiration rate of the plant is smaller than it is in winter (in order to conserve water and avoid heat stress).

The effect of evapotranspiration is minimal during the heating season, particularly for increased wind speeds (the results presented here are for a typical plant, but when considering that deciduous trees have no leaves in winter, evapotranspiration will be lower than shown here, as in the case of reduced solar gains).

With respect to leaf temperature the strongest effect is wind speed. As wind speed increases, leaf temperature decreases for the same air temperature.

\subsection{Parametric studies using CFD}

The generic urban textures that were employed for the CFD analysis, are tested with and without vegetation of different sizes for typical climatic conditions of Athens, height to width ratio and corresponding sky view factor representative of central Athens, derived from two case study sites examined in the project. The thermal and airflow conditions are then analysed with respect to:

(i) density of the urban texture;

(ii) sky view factor;

(iii) size of the green area;

(iv) distance from the green area;

(v) climatic conditions;

(vi) vegetation specie.

\subsubsection{Urban layout for parametric studies}

The basic morphology of the different parametric studies is presented in Fig. 3. Each building is $10 \mathrm{~m} \times 10 \mathrm{~m}, 15 \mathrm{~m}$ high, whereas the width of the street between buildings is 


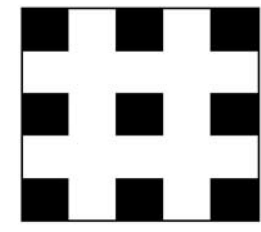

Base case (A)

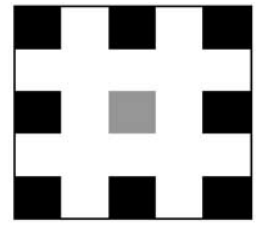

Case (B)

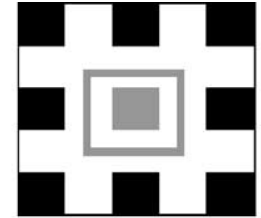

Case (C)

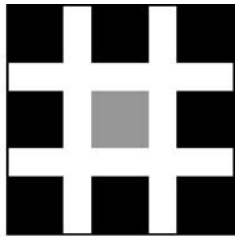

Case (D)

Fig. 3. Generic urban textures.

also $10 \mathrm{~m}$. The initial height to width ratio for the street canyon is 1.5 , whereas unless otherwise stated, the testing environmental conditions refer to $25^{\circ} \mathrm{C}$ input air temperature, wind speed of $1 \mathrm{~m} / \mathrm{s}$ at the upper limit of the boundary layer and a wind direction of $0^{\circ}$ (south).

More specifically, the different runs are presented below:

1. base case (a), buildings only;

2. case (b), where the central building is replaced by a park of similar dimensions, $10 \mathrm{~m} \times 10 \mathrm{~m}$;

3. similar to (1), with a row of trees of the same area to the park, $2 \mathrm{~m} \times 50 \mathrm{~m}$, perpendicular to the airflow;

4. similar to (2), with a wind speed of $2.4 \mathrm{~m} / \mathrm{s}$ at the upper limit of the boundary layer;

5. similar to (2), with $30{ }^{\circ} \mathrm{C}$ input air temperature and a wind speed of $2.4 \mathrm{~m} / \mathrm{s}$ at the upper limit of the boundary layer;

6. similar to (2), with wind coming at $45^{\circ}$ angle;

7. case (c), where the size of vegetation increases to $14 \mathrm{~m} \times 14 \mathrm{~m}$, almost double the area of the base case;

8. similar to (7), with vegetation size increasing to $18 \mathrm{~m} \times 18 \mathrm{~m}$, more than triple the area of the base case;

9. similar to (7), with different vegetation characteristics;

10. case (d), where both the buildings and vegetation size increases to $14 \mathrm{~m} \times 14 \mathrm{~m}$, increasing $\mathrm{H} / \mathrm{W}$ of the street from 1.5 to 2.5 ;

11. similar to (10), with wind coming at $45^{\circ}$ angle;

12. similar to (10), where the size of vegetation increases to $18 \mathrm{~m} \times 18 \mathrm{~m}$, with a wind direction of $0^{\circ}$ angle;

13. similar to (10), with different vegetation characteristics.

A 3D mathematical model was developed [7], in order to predict the flow patterns and temperature distribution around a group of buildings. To account for the effects of the surrounding buildings to the wind flow in a real life situation, rows of buildings of similar dimensions have been added around the basic urban cell, as shown in Fig. 4. Extra space is

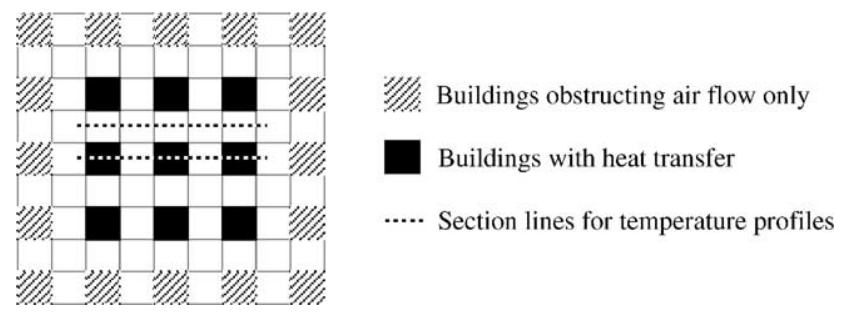

Fig. 4. Layout of the analysis grid. reserved downwind of the buildings' structure (more than seven times the building height), in order to account for the correct representation of the wake effects.

\subsubsection{Assumptions for vegetation and climatic input}

In order to examine the maximum possible effect of evapotranspiration in reducing air temperatures in the urban context, the following assumptions have been made.

(i) Regarding the state of vegetation, it is assumed that the park is well watered, avoiding any water stress, which would result in reduced evapotranspiration of the plant.

(ii) The air is introduced in the model at a temperature of $25^{\circ} \mathrm{C}$, as in the Section 4.1.1, the "mathematical plant" demonstrated that maximum evapotranspiration rate occurs at ambient air temperature of $25^{\circ} \mathrm{C}$.

(iii) The wind speed, at the upper limit of the boundary layer, at a height of $120 \mathrm{~m}$, is $1 \mathrm{~m} / \mathrm{s}$, resulting to near calm conditions near the ground. This is also in agreement to the findings of the "mathematical plant", where at very low wind speeds, transpiration rate is greater. Runs with a resulting wind speed of $1 \mathrm{~m} / \mathrm{s}$ at $1.5 \mathrm{~m}$ above ground $(2.4 \mathrm{~m} / \mathrm{s}$ outside the interrupted wind flow boundary) have also been carried out, to examine the disruption of airflow in the area and resulting air temperatures.

\subsubsection{Assumptions for boundary conditions and heat transfer}

The heat transfer from the building envelope, as well as from the roads and the park to the ambient air is modelled with the use of "fixed thermal energy flux" boundary conditions. The fluxes have been determined according to the following assumptions [7]:

(i) the irradiance values for the different geometrical configurations have been calculated using radiance ray tracing techniques (by Ecole d'Ingénieurs et d'Architectes de Fribourg, Switzerland, a member of the PRECis team), assuming the Athens Statistical Sky for July [8];

(ii) a surface reflectance value of 0.25 has been assumed, for ground and building surfaces;

(iii) no heat losses to the ground have been assumed, so that all the absorbed solar energy is conveyed to the 
ambient air as sensible heat (no ground heat losses due to nearly thermal equilibrium during the summer);

(iv) the evapotranspiration (latent heat and mass transfer) from the plants forming the park are modelled as enthalpy sinks of the same magnitude to the latent heat absorbed, expressed as "per unit volume;"

(v) The above-mentioned enthalpy sinks correspond to $2.45 \mathrm{~kg}$ water $/ \mathrm{m}^{2}$ per day for normal plants and $4.2 \mathrm{~kg}$ water $/ \mathrm{m}^{2}$ per day for tropical plants, as calculated from Eq. (1), with a cover factor of $90 \%$;

(vi) vegetation is modelled with a permeability, as described in the Section 3.4, obstructing the airflow;

(vii) the finite-domain equations are employed;

(viii) the grid structure consists 60 cells in the $x$ - and $y$ direction, and 33 cells in the $z$-direction, concentrated near the ground to account for "wall effects".

\section{Results}

The most important findings are presented below, plotted in different sets of graphs: temperature profiles along the street next to the park (Figs. 5 and 6) and through the centre of the site, i.e. through the park (Figs. 7 and 8), $1.5 \mathrm{~m}$ high from the ground. This way the resulting reduced air temperatures, due to the effect of vegetation, can be examined with location and relative distance from the park. The horizontal axis represents the distance from the edge of the analysis grid, $70 \mathrm{~m}$ being the windward face of the first studied row of buildings (Fig. 4).

The following legend is used to facilitate the discussion:

A case (a), buildings only;

AT case (a), with row of trees;

B $\quad$ case (b), park of $10 \mathrm{~m} \times 10 \mathrm{~m}$;

BB case (b), at $45^{\circ}$ angle;

B24 case (b), with higher wind speed $(2.4 \mathrm{~m} / \mathrm{s})$;

B24-30 case (b), with higher wind speed and ambient air temperature of $30^{\circ} \mathrm{C}$;

C1 $\quad$ case (c), park of $14 \mathrm{~m} \times 14 \mathrm{~m}$;

C2 case (c), park of $18 \mathrm{~m} \times 18 \mathrm{~m}$;

C1T case (c), with tropical vegetation;

D1 case (d), buildings and park of $14 \mathrm{~m} \times 14 \mathrm{~m}$;

DD case (d), at $45^{\circ}$ angle;

D2 $\quad$ case (d), park of $18 \mathrm{~m} \times 18 \mathrm{~m}$;

D1T case (d), with tropical vegetation.

\subsection{Size of green area}

Increasing the size of the green area produces the greatest reduction of ambient air temperature, particularly when compared to the base case (Figs. 5 and 7; A, AT and B). A row of trees inserted to the basic urban texture (A and AT), decreases air temperature by $1 \mathrm{~K}$ (Figs. 5 and 7).

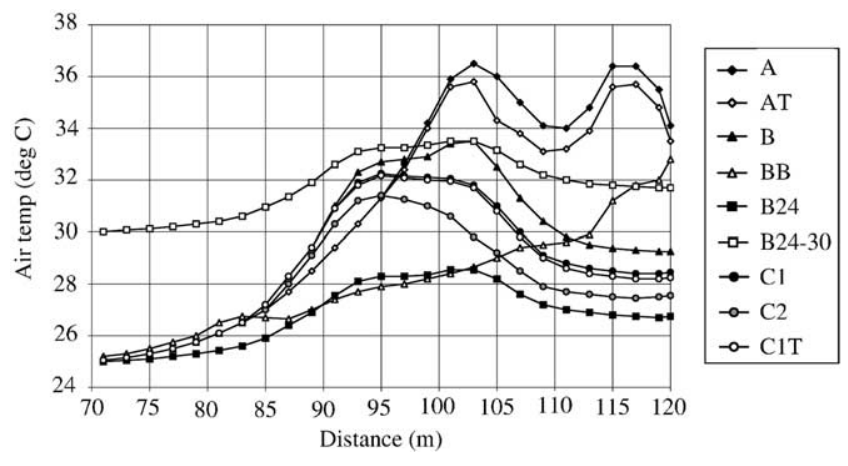

Fig. 5. Temperature profiles along the street for variations of cases (a), (b) and (c).

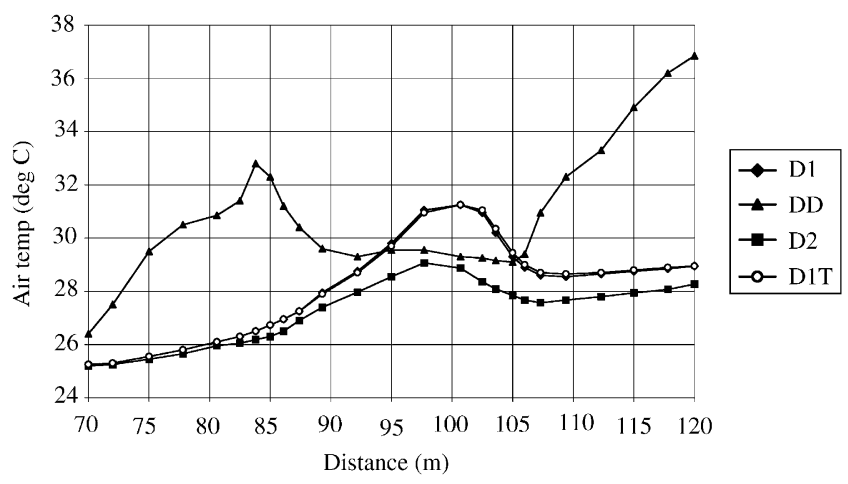

Fig. 6. Temperature profiles along the street for variations of case (d).

Replacing the central building with a park (A and B), leads to reduction of temperature from $2 \mathrm{~K}$, behind the park (Fig. 7), to more than $6 \mathrm{~K}$, at the street parallel to the park, at the leeward side of the park (Fig. 5). It has to be kept in mind however, that the effect of the park alone, should be smaller, as this difference is also due to the fact that a heat sourcecentral building in A—is replaced by a heat sink-park in B.

Increasing the size of the park to double its original area (C1) leads to further reduction of air temperature of $1 \mathrm{~K}$ (Figs. 5 and 7). Increasing the size of the park to more than three times its original area $(\mathrm{C} 2)$ leads to further reduction of air temperature to $1.5-3 \mathrm{~K}$ (Figs. 5 and 7).

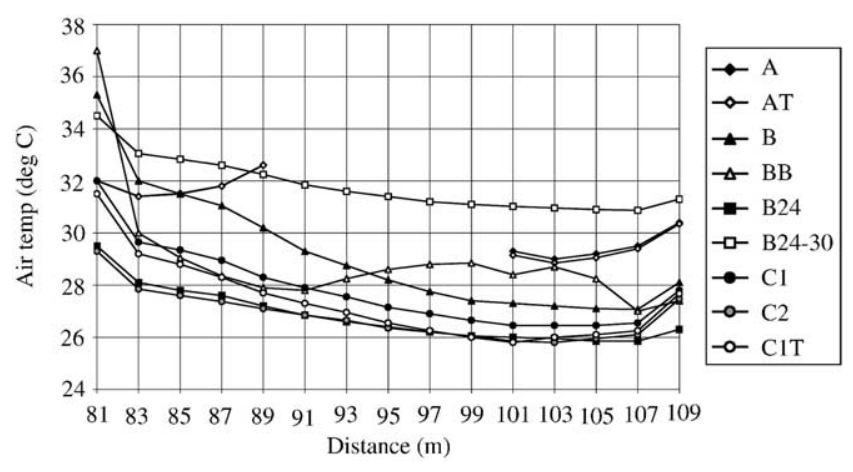

Fig. 7. Temperature profiles through centre-line for variations of cases (a), (b) and (c) 


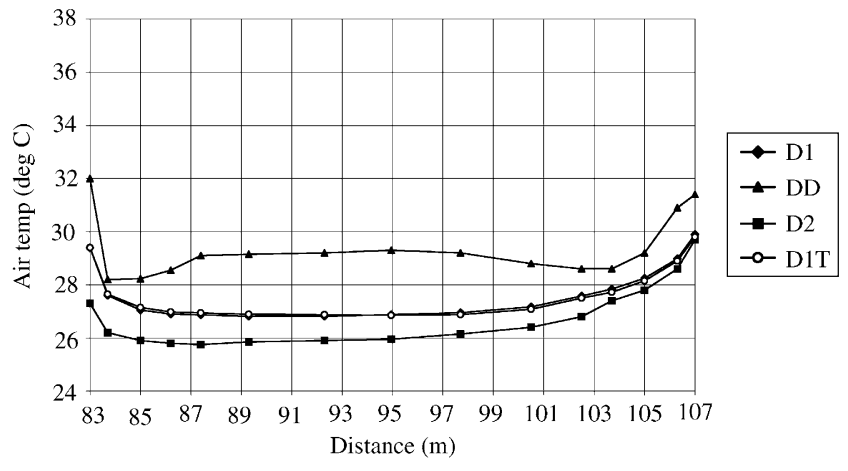

Fig. 8. Temperature profiles through centre-line for variations of case (d).

Increasing the size of the park to the more dense urban fabric (D1 and D2; Figs. 6 and 8), similarly reduces air temperatures from 1 to $2 \mathrm{~K}$, in the street parallel to the park and 0.5 to $1 \mathrm{~K}$, behind the park. The reason for the latter difference being smaller than the corresponding $\mathrm{C} 1$ and $\mathrm{C} 2$ cases, $1 \mathrm{~K}$, is described below.

\subsection{Density of the urban texture}

In the more dense urban texture (D1 and D2) air temperature is higher behind the park and lower in the street parallel to the park (Fig. 8), than in $\mathrm{C} 1$ and $\mathrm{C} 2$ cases (Fig. 7). As the H/W ratio of the street increases, the wake effect increases too and therefore, mixing of air is reduced. This keeps the effect of the park relatively local, while the area behind the park is also affected by the heat radiated from the south façade of the rear building. This aerodynamic shading is also apparent with the heat accumulated between the buildings, across the wind direction. Therefore in D1 and D2 cases, the heat is trapped between the buildings, particularly as wind speed is very low, and air in the street parallel to the park, is mainly affected by the park (Fig. 6). On the contrary, in $\mathrm{C} 1$ and $\mathrm{C} 2$ cases, hot air from the nearby buildings, raises the temperature of the street due to better mixing conditions (Fig. 5).

\subsection{Orientation}

Two tests were carried out with wind direction of $45^{\circ}$, for case (b) BB and case (d) DD. The results seem to suggest that we get the biggest temperature difference at the street parallel to the park, particularly near the park, $5 \mathrm{~K}$ for $\mathrm{BB}$ and $2 \mathrm{~K}$ for DD cases (Figs. 5 and 6 ). This can be attributed to the good mixing of the different air streams.

On the contrary, at the area through the centre of the site, air temperature with wind running at $45^{\circ}$ is higher than at $0^{\circ}$ angle. For cases $\mathrm{BB}$ and DD, air temperature is 1 and $2 \mathrm{~K}$ higher than for B and D cases, respectively (Figs. 7 and 8). This must be due to the fact that for wind blowing at $45^{\circ}$ the park is more exposed to the wind and not protected from the buildings at the front, as in B and D cases.

\subsection{Different kinds of vegetation}

Replacing vegetation in the park with trees of different kind, i.e. tropical, with higher evapotranspiration rate, does not seem to have a big effect (less than $0.5 \mathrm{~K}$ ), for the same area, C1T and D1T cases.

\subsection{Different wind speeds}

When wind speed is increased to $1 \mathrm{~m} / \mathrm{s}$ at $1.5 \mathrm{~m}$ above ground $(2.4 \mathrm{~m} / \mathrm{s}$ at the upper limit of the boundary layer) the effect of vegetation seems to be decreased. In this case, ambient air temperature profiles closely follow the temperature at which the wind is introduced in the area-B24 wind introduced at $25^{\circ} \mathrm{C}$ and B24_30 wind introduced at $30{ }^{\circ} \mathrm{C}$ (Figs. 5 and 7).

\subsection{Distance from green area}

Another important point requiring consideration is how far around the park, the effect of vegetation extends. This is also best viewed at the temperature profiles presented in Figs. 5-8. Generally, the effect of vegetation extends to the end of the site boundaries at the leeward side. The wind carries the cool air from the park and the air temperature drops steadily, particularly at the street parallel to the park (Figs. 5 and 6).

In the centre-line through the park, the effect of the park still extends behind the park, with an increase of air temperature before reaching the final row of buildings-heat sources (Figs. 7 and 8). This increase is greater for the dense urban texture, 3-4 K, due to the narrower streets, where hot air from the building surface immediately affects the cool air from the park (Fig. 8). For cases B and C the wider streets mean that the cool air is carried further back and is mixed well before reaching the building surface, therefore the air temperature increase is 1 and $2 \mathrm{~K}$, for cases $\mathrm{B}$ and $\mathrm{C}$, respectively.

Another interesting point is that although the air temperature profiles drop steadily at the leeward side of the park, their magnitude is different at the centre-line and the street parallel to the park. Absolute minimum air temperature is found at the rear of the park (Fig. 7), and is around $2 \mathrm{~K}$ lower than at the street parallel to the park, whereas in the dense urban texture the absolute minimum air temperature is found inside the park (Fig. 8).

\subsection{Summary}

It is apparent that vegetation can greatly influence the thermal microclimate in the urban texture. This affects the area within the park as well as the surrounding area, particularly at the leeward side of the green area.

To demonstrate this effect clearly, the results have been summarised and presented in a different way. The effective area of the park is plotted against the reduction of air 


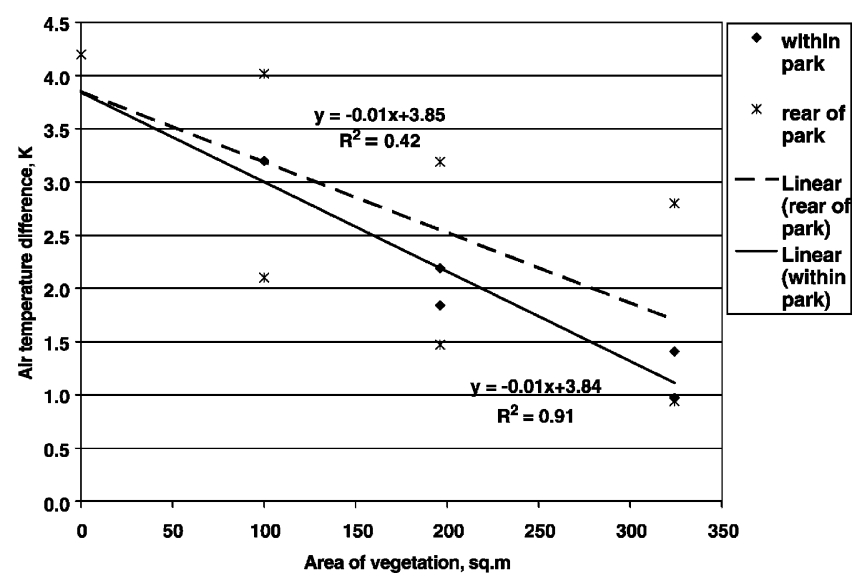

Fig. 9. Reduction of air temperature within the park and at the leeward side of it, from the use of vegetation.

temperature that is observed within the park and at the street at the leeward side of it, from the use of vegetation (Fig. 9). This temperature difference is obtained from the resulting air temperature in the area under consideration and the ambient air that was used as an input to the model, i.e. $25^{\circ} \mathrm{C}$.

It is apparent that the effective area of vegetation greatly influences air temperature within the park area. More specifically, the results seem to suggest that an average temperature reduction of around $1 \mathrm{~K}$ can be expected for every $100 \mathrm{~m}^{2}$ of vegetation added to the park.

More importantly, however, this effect extends outside the boundaries of the park, at the leeward side of it, reducing air temperature at the neighbouring street (Fig. 9). This is also verified by the parametric runs carried out with a wind direction of $45^{\circ}$ where the greatest temperature reduction of all was obtained at the leeward side of the park (cases BB and DD; Figs. 5 and 7).

However, the correlation for the street behind the park is not as strong as for within the park, as in the street, air temperature is also greatly influenced by the surrounding built structures. Thus, in the parametric studies carried out, for the same vegetation area, built area varies as:

(i) for vegetation of $100 \mathrm{~m}^{2}$, we have cases AT and B;

(ii) for vegetation of $196 \mathrm{~m}^{2}$, we have cases $\mathrm{C} 1$ and D1;

(iii) for vegetation of $324 \mathrm{~m}^{2}$, we have cases $\mathrm{C} 2$ and D2.

It is appropriate to present the reduction of air temperature between the resulting air temperature and $25^{\circ} \mathrm{C}$ at points on the leeward side of the park, as a function of built area as well as vegetation area. A ratio of green to built area is therefore calculated, which is the area of vegetation divided by the total built area, for the different cases.

It is important to mention that only cases A, AT, B, C1, $\mathrm{C} 2$, D1 and D2 are considered, as the comparison has to be made on an equal basis, i.e. same wind speed, orientation and ambient air temperature introduced in the model.

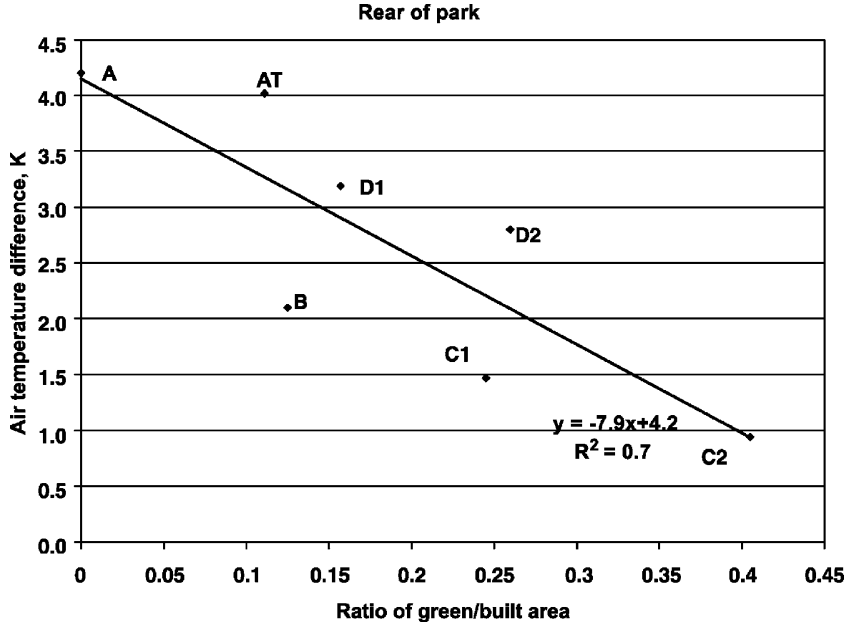

Fig. 10. Reduction of air temperature at the leeward side of the park, in relation to the green to built area ratio.

The results, presented in Fig. 10, clearly demonstrate the beneficial effects of vegetation to the microclimate of the street at the leeward side of the park, to be read as a trend rather than providing absolute air temperatures. Therefore, the higher the ratio of green to built area in an urban texture the greater the air temperature reduction is to be expected in the area. As a rule of thumb, a $0.8 \mathrm{~K}$ reduction in ambient air temperature is to be expected for a $10 \%$ increase to the ratio of green to built area, for the urban textures under consideration.

In effect, it is shown that vegetation assists in warming the air less in the urban texture, in agreement to measurements of field studies, as mentioned in the beginning of this paper.

\section{Conclusions}

This paper has shed some light on the thermal effects of vegetation in the urban environment, demonstrating that it can greatly improve the urban microclimate, as well as mitigate the heat island effect, by reducing summer air temperatures. This effect is noticed not only within the boundaries of the green area, but extends beyond the park itself, particularly affecting the leeward side of it. Therefore, increasing vegetation in the urban context can be an effective way of mitigating the heat island, and benefit urban centres.

\section{Acknowledgements}

This work was carried out for the 'PRECis' EU Joule project (JOR3-CT97-0192) from February 1998 to September 2000, co-ordinated by Koen Steemers at the Martin Centre, University of Cambridge. It was co-funded by the European Union (DG XII) and the General Secretary of 
Research and Development of the Greek Ministry of Development.

\section{References}

[1] D.K. Kurn, S.E. Bretz, H. Akbari, The potential for reducing urban air temperatures and energy consumption through vegetative cooling, in: Proceedings of the 1994 Summer Study on Energy Effects in Buildings, Pacific Grove, California, 1994.

[2] H. Akbari, S. Davis, S. Dorsano, J. Huang, S. Winnett (Eds.), Cooling Our Communities: a Guidebook on Tree Planting and Light-Colored Surfaces, US Environmental Protection Agency, 1992.
[3] http://www.agen.tamu.edu/pet/tools/crop/.

[4] R. Jensen, H. Haise, Estimating evapotranspiration from solar radiation, irrigation drainage division, American Society of Civil Engineers 89 (1963) 15-41.

[5] G. Stanhil, G.H. Hofstede, J.D. Kalma, Radiation balance of natural and agricultural vegetation, Quarterly Journal of Royal Metal Society 92 (1966) 128-140.

[6] Mathematical Plant: Transpiration model Developed and Distributed by Terence Murphy, at the University of California, Davis.

[7] A. Karayannis, E. Keramida, J. Panagopoulos, Prediction of Wind Patterns and Temperature Distribution in an Urban Environment Progress Report for CRES, 1999.

[8] R. Compagnon, Solar and Daylight Availability in Urban Areas, EIF Final Report for the PRECis Project, 2000. 